Fourth International Conference on Sustainable Construction Materials and Technologies

http://www.claisse.info/Proceedings.htm

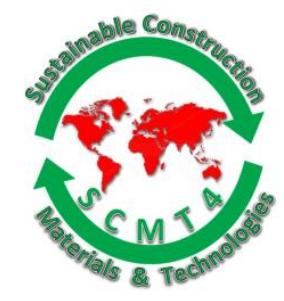

SCMT4

Las Vegas, USA, August 7-11, 2016

\title{
Sustainability of Construction Materials in Bangladesh
}

\author{
Tarek U. Mohammed ${ }^{1 a}$, Aziz H. Mahmood ${ }^{1 b}$, Ijaj M. Chowdhury ${ }^{1 c}$, \\ Akter M. Humayun ${ }^{2}$, and Tanvir Ahmed ${ }^{1 d}$ \\ ${ }^{1}$ Department of Civil and Environmental Engineering, Islamic University of Technology (IUT), \\ Organisation of Islamic Cooperation (OIC), Board Bazar, Gazipur-1704, Bangladesh. ${ }^{\text {la Email: }}$ \\ <tarek@iut-dhaka.edu>, ${ }^{1 b}$ Email: <hasancee@iut-dhaka.edu>, ${ }^{1 c} E m a i l:<i j a j c e e @ i u t-d h a k a . e d u>$, \\ ${ }^{1 d}$ Email: <tanvirbd@iut-dhaka.edu>. \\ ${ }^{2}$ Rashed Kanchan Corporation, H\#58, Road\#1, Niketon, Gulshan 1, Dhaka, Bangladesh. \\ ${ }^{2}$ Email: <aktarkiron.rkc@gmail.com>.
}

\begin{abstract}
The global high growth rate of population and economic development has led to an increased volume of concrete consumption each year. Roughly around 18 billion metric tons of concrete is consumed globally each year. Consumption of such a huge volume of construction materials for making new infrastructures may create a sustainability crisis in the near future. This is also a concern for developing countries like Bangladesh. For sustainable development of concrete construction materials in Bangladesh, research works on several important issues were carried out, such as (1) understanding of main causes of deterioration of concrete structures in Bangladesh, (2) identification of problems at construction sites that causes early deterioration of concrete structures in Bangladesh, (3) understanding of deterioration of concrete structures due to chloride and carbonation induced corrosion, (4) utilization of mineral by-product in cement, and (5) recycling of demolished concrete as coarse and fine aggregates, (6) utilization of brick fine aggregate in concrete, and (7) utilization of induction furnace slag as coarse aggregate. Several important conclusions are drawn based on these studies that will play a vital role for sustainable use of concrete construction materials in Bangladesh.
\end{abstract}

\section{INTRODUCTION}

World demand for cement and concrete additives is projected to be increased by $8.3 \%$ annually [World cement and concrete additives 2012]. In the developing markets, this growth will be boosted due to the needs for development activities related to construction of infrastructures. Global volume of cement demand has doubled over the last decade, from 1.8 billion tons in 2002 to 3.7 billion ton in 2012 [Armstrong 2013]. With the increasing demand of concrete, the demand for aggregates is also increasing at a very high rate. Globally, the demand for aggregates in 2013 is estimated at more than 20 billion metric tons. This demand will increase by $2.9 \%$ [World construction aggregate 2009] annually. It is also found that in the Asia-Pacific region, the demand will be increased in a faster rate. Soon, there might be a crisis of virgin aggregates. Finding sustainable solutions in order to continue the pace of development in the construction industry would be a time befitted step in this regard. 
Bangladesh cement industry is the $40^{\text {th }}$ largest market in the world having a capacity of just over 25 million metric tons per year, whereas the global production is almost 4000 million metric tons per year. Currently the rate of consumption of cement is about $110 \mathrm{~kg} / \mathrm{capita} /$ year in Bangladesh and the rate is increased by 20-25\% every year [Nayan 2013]. To avoid scarcity of construction materials, it is very urgent to explore the issues related to the sustainability of concrete construction materials. With this background, this study is continuing since 2005 and the following items were investigated that will eventually contribute to the sustainable development of construction materials in Bangladesh:

- Understanding the causes of deterioration of concrete structures in Bangladesh,

- Problems at construction sites that cause early deterioration of concrete structures in Bangladesh,

- Carbonation rate of concrete structures in Bangladesh,

- Utilization of blended cement to reduce demand for clinker,

- Recycling of demolished concrete as coarse and fine aggregate for new construction works to reduce demand for virgin aggregates,

- Utilization of brick fine aggregate in concrete, and

- Utilization of induction furnace slag as coarse aggregate.

\section{CAUSES OF DETERIORATION OF CONCRETE STRUCTURES IN BANGLADESH}

At the beginning step toward sustainability, it is necessary to understand the main reasons of deterioration of concrete structures. Therefore, to understand the possible causes of deterioration of concrete structures in Bangladesh, a detailed survey of deteriorated buildings in several districts were carried out [Mohammed 2013a]. Based on the survey results, the main causes of deterioration of concrete structures in Bangladesh are summarized below:

- Carbonation induced corrosion of steel bars

- Chloride induced corrosion of steel bars

- $\quad$ Drying shrinkage

- $\quad$ Mud in aggregate

- Differential settlement

- $\quad$ Efflorescence in brick

- Thermal expansion

- $\quad$ Sulfate/chemical attack

- Water logging on roofs

- $\quad$ Lack of maintenance

Carbonation induced corrosion of steel in concrete is found to be the main reason of deterioration of concrete structures in Bangladesh. Further study on the rate of deterioration of concrete structures due to carbonation induced corrosion was carried out and summarized later. It is understood that high temperature, high humidity and poor quality of construction works cause a higher rate of carbonation of structures in Bangladesh and finally lead to early deterioration by carbonation induced corrosion of steel in concrete. In the marine environment, it was also found that chloride induced corrosion of steel in concrete is the main reason for deterioration of concrete structures.

\section{PROBLEMS AT CONSTRUCTION SITES THAT CAUSE EARLY DETERIORATION OF CONCRETE STRUCTURES IN BANGLADESH}

Several construction sites were visited to identify the causes associated with the early deterioration of concrete structures. The problems identified at the construction sites are listed below [Mohammed 2013a]: 
-Use of un-sieved aggregates

-Use of un-washed aggregates

-Use of mud mixed water for mixing concrete

- Use of rusted reinforcement in construction

-Use of excess water (high W/C) to mix concrete

- Use of excess sand in concrete

-Inappropriate compaction

- Inappropriate curing

-Efflorescence on bricks
- Use of excess amount of coarse aggregate

- Poor mixture proportion of concrete

- Problems associated with volumetric mix proportions

- Lack of cover concrete

- Problems associated with formwork (leakage of mixing water)

- Placing of concrete from a large height by labors

- Poor workmanship

- Construction by unskilled workers

- Inappropriate storing of construction material

To improve the quality of concrete, it is necessary to take actions against the problems as listed above. It is also necessary to note that volumetric mix proportions are generally used for most of the construction works except concrete supplied by the ready mix concrete industries. Generally, mix proportions for concrete are set at 1:1.5:3 (for compressive strength $20 \sim 27.5 \mathrm{MPa}$ ) or 1:2:4 (compressive strength $17-20 \mathrm{MPa}$ ) for most of the construction works. The amount of water for concrete works is recommended at 25 liters per bag of cement as per Bangladesh National Building Code (BNBC). Unfortunately, at the construction sites, water is added till the mix become workable without any measure of the amount of mixing water. The use of a high W/C makes concrete relatively porous and consequently creates easy paths for ingress of harmful constituents into concrete in addition to the reduction of strength. In many construction sites, unskilled workers are involved. It is impossible to achieve sustainability without the input of skilled workers in construction. Initiatives are also necessary to create authorized engineers for concrete works. Also, skilled construction workers are to be created through proper training. Moreover, seminars, workshops, and conferences are to be organized to disseminate the knowledge related to concrete technology among the engineers and other professionals involved in concrete related works.

\section{DETERIORATION OF CONCRETE STRUCTURES DUE TO CARBONATION INDUCED CORROSION}

It is found that concrete floors, beams, and columns are severely damaged due to the corrosion of steel bars in concrete after 10 15 years of service life. Carbonation of concrete is the main reason behind this problem due to the high humidity $\left(60 \%\right.$ 95\%) and high temperature $\left(40^{\circ} \mathrm{C}\right.$ in summer) in Bangladesh. The use of low strength concrete (less than $20 \mathrm{MPa}$ ) and poor quality concrete works at the construction site also accelerates the process of carbonation. To determine the carbonation coefficient of concrete, carbonation depth of concrete in structural elements was determined for both indoor and outdoor exposures [Mohammed et al 2013b]. The variation of depth of carbonation with the age of the buildings is shown in Figure 1. Generally, the depth of carbonation is expressed by the following equation.

$$
D=K \sqrt{t}
$$

Where $\mathrm{D}$ is the depth of carbonation in $\mathrm{mm}, \mathrm{k}$ is the carbonation coefficient in $\mathrm{mm} /$, and $\mathrm{t}$ is the time in year. The average carbonation coefficient was found to be 3.36 and 4.16 in indoor and outdoor exposure respectively. The result indicates that, for 100 years of service life, the minimum cover of concrete in indoor and outdoor exposure condition is to be $34 \mathrm{~mm}$ and $42 \mathrm{~mm}$ respectively. In general, for slabs cover concrete is specified to be $20 \mathrm{~mm}$. Also, relatively low strength concrete is used for slabs. As a result, within a short period of time, spalling of cover concrete of slab is found due to carbonation induced corrosion. Cover thickness of slab is to be increased from the currently specified value in the design code. Alternatively, it 
is necessary to increase the strength of slab concrete. The results related to the carbonation induced corrosion were summarized separately [Mohammed et al 2013b].

\section{REPLACEMENT OF CEMENT BY MINERAL ADMIXTURES}

As per BDS EN 197, twenty-seven (27) cement types are specified with and without mineral admixtures. However, cement with large quantity of mineral admixtures is rarely found in the market and therefore it is necessary to do more investigations on blended cement to make general confidence of engineers to use it in construction works. An experiment was conducted using different types of cement (with and without mineral admixtures) after collection from the market in Bangladesh. The compositions of cement which were collected for investigations are listed below:

$\begin{array}{ll}\text { CEM I } & : 95 \% \text { Clinker } \\ \text { CEM II/A-M } & : 20 \% \text { Mineral admixture (maximum) plus clinker } \\ \text { CEM II/B-M } & : 35 \% \text { mineral admixture (maximum) plus clinker } \\ \text { CEM II/A-S } & : 20 \% \text { ground granulated blast furnace slag (maximum) plus clinker } \\ \text { CEM II/A-L } & : 20 \% \text { limestone powder (maximum) plus clinker }\end{array}$

The result of variation of strength for different types of cement is shown in Figure 2. It can be seen that compressive strength of cement is increased with age irrespective of the type of cement. OPC cement (CEM I) shows relatively higher strength compared to the other cements (CEM II/A-M, CEM II/B-M, CEM II/AS, CEM II/A-L) at the early age, the strength of mortar specimen is lower for other cements compared to OPC cement. But this difference of strength is reduced with time. The difference of strength is high with the increase of mineral contents in cement. It is expected that the strength of blended cement will increase with time further and will compete with the strength of OPC cement and exceed the strength of OPC cement in the long run. Table 1 shows the conversion factor for estimating compressive strength from early age to later age. It can be seen that conversion factor is higher for the cement made with a large amount of mineral admixtures. Thus blended cement gives higher strength with less heat of hydration and makes the concrete denser with time and minimize clinker consumption, consequently it will contribute greatly to the sustainable development. The results of this investigation were reported separately [Mohammed 2012].

Table 1. Strength Conversion Factors for Different Cements

\begin{tabular}{|c|c|c|c|}
\hline \multirow{2}{*}{ Type of Cement as per BDS EN 197 } & \multicolumn{3}{|c|}{ Strength Conversion Factor } \\
\cline { 2 - 4 } & 3 to 28 Days & 7 to 28 Days & 14 to 28 days \\
\hline CEM I & 1.51 & 1.26 & 1.10 \\
\hline CEM II/A-M & 1.57 & 1.30 & 1.13 \\
\hline CEM II/B-M & 1.77 & 1.37 & 1.15 \\
\hline CEM II/A-S & 1.69 & 1.34 & 1.15 \\
\hline CEM II/A-L & 1.64 & 1.33 & 1.16 \\
\hline
\end{tabular}




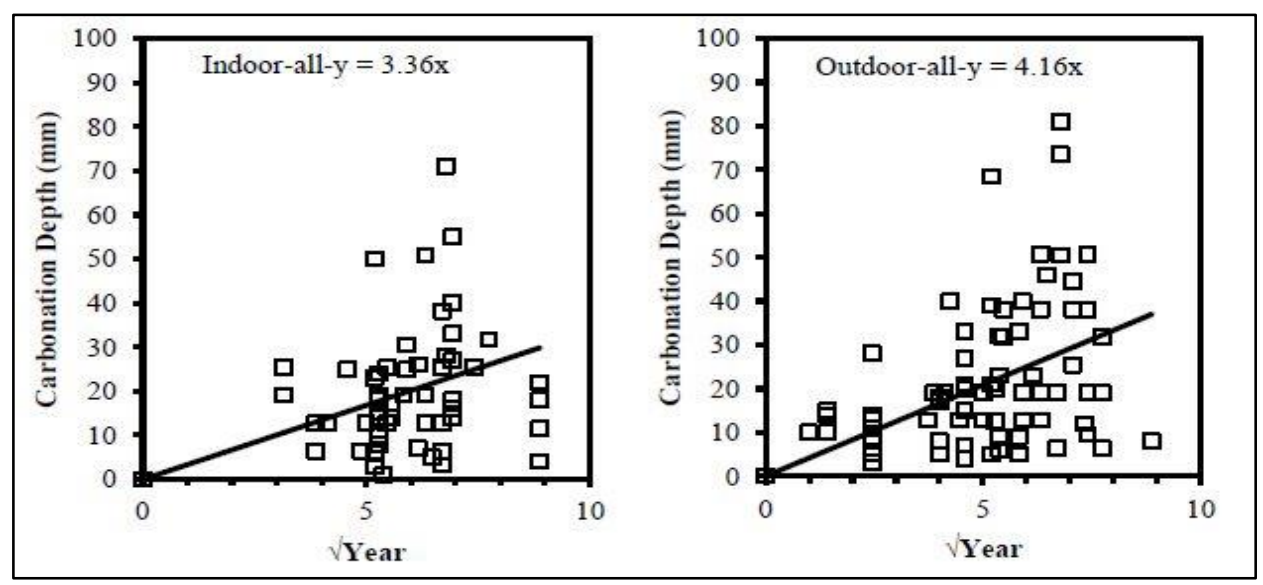

Figure 1. Relationship Between Depth of Carbonation and Age of Structure

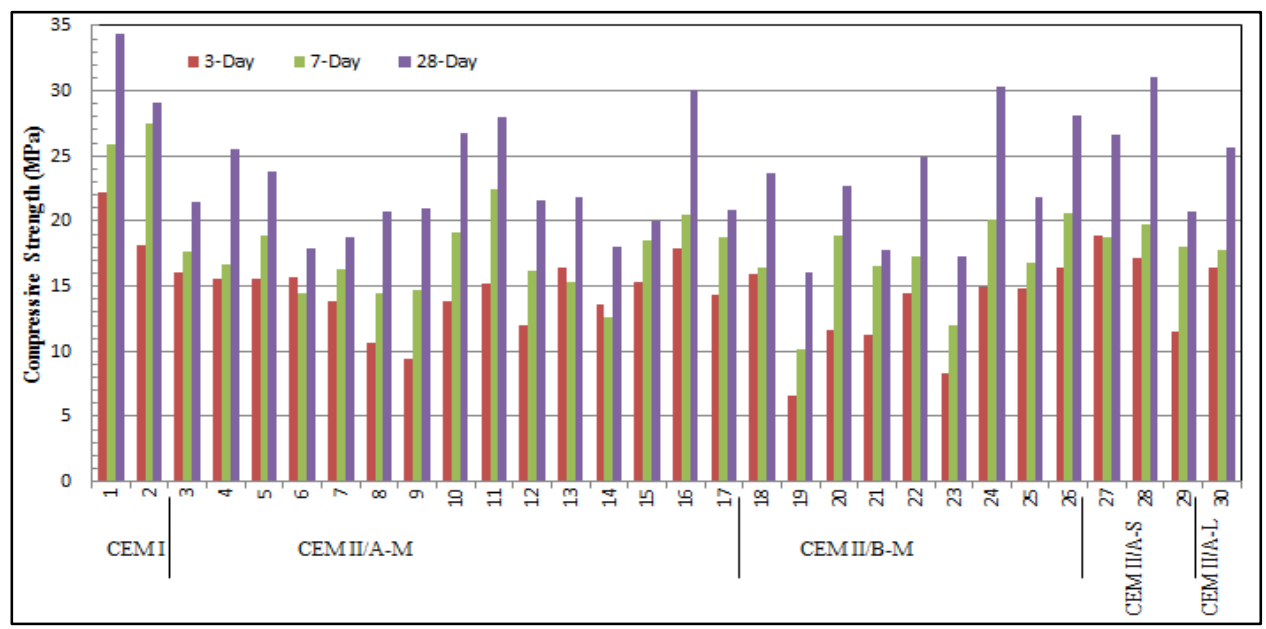

Figure 2. Compressive Strength of Cement of Different Composition with Age

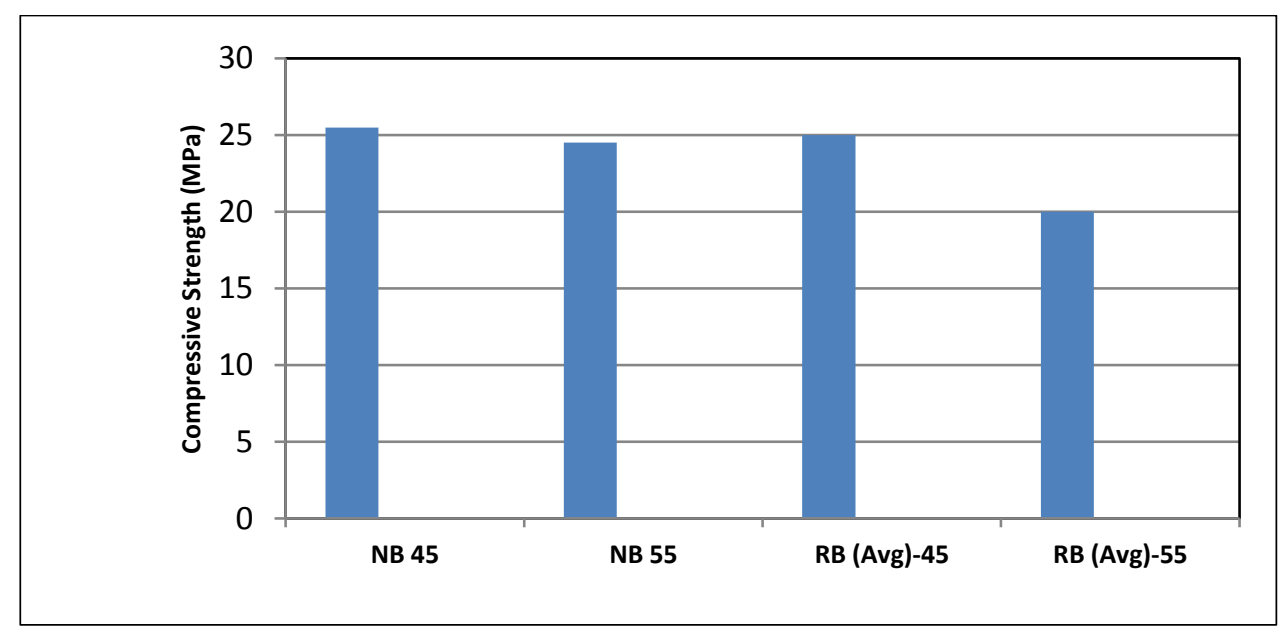

Figure 3. Compressive Strength of Concrete 


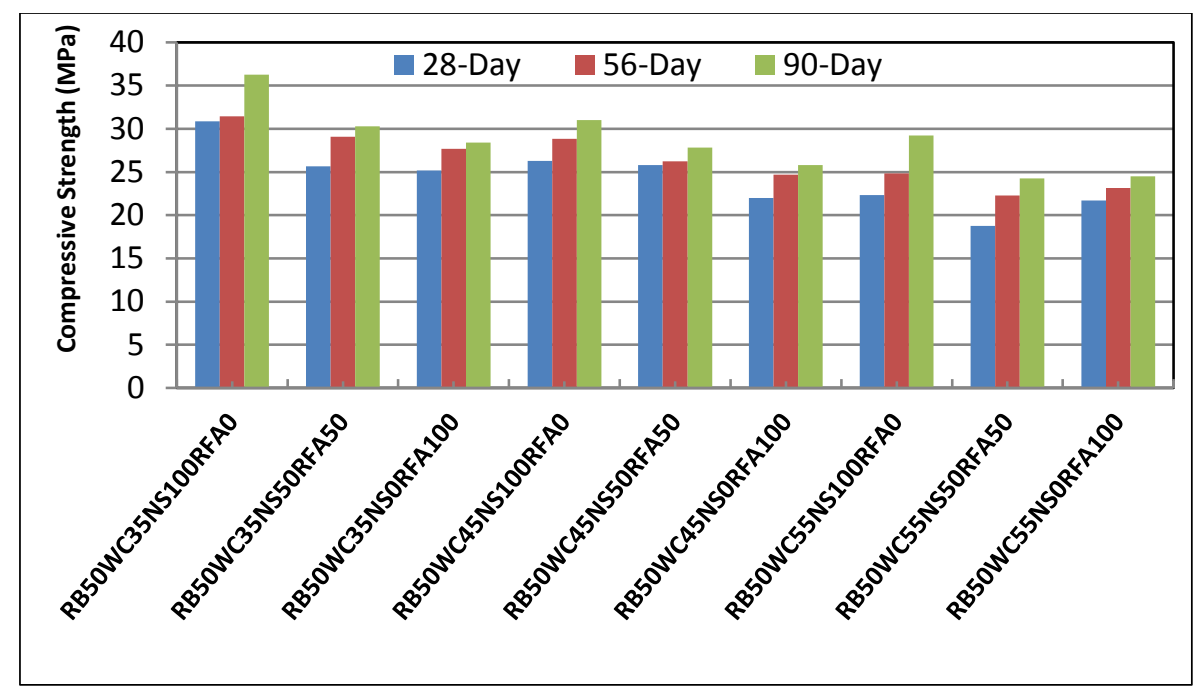

Figure 4. Compressive Strength of Concrete Made with Recycled Aggregate of Age 50 Years

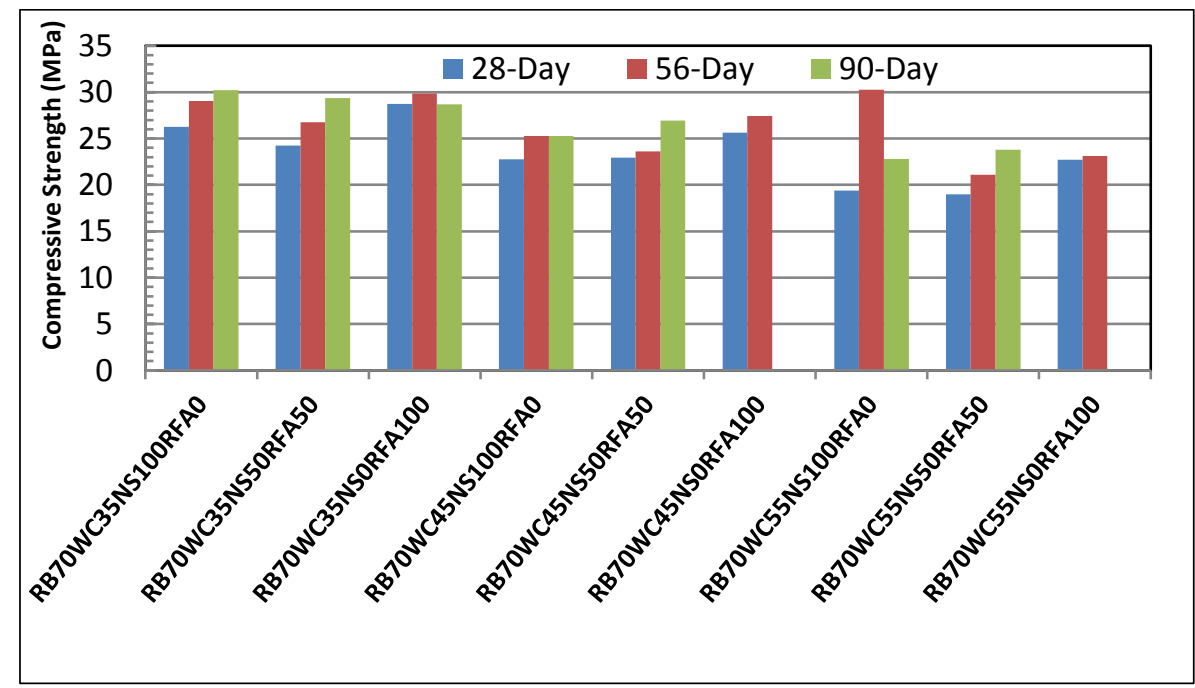

Figure 5. Compressive Strength of Concrete Made with Recycled Aggregate of Age 70 Years

\section{RECYCLING OF DEMOLISHED CONCRETE AS COARSE AND FINE AGGREGATES}

The volume of demolished concrete in Bangladesh is also increasing day by day due to the aging of infrastructure as well as replacement of low rise buildings by relatively high rise buildings due to the booming of real estate business. Therefore, an attempt was made to find out the possible ways for recycling of demolished concrete for new construction as coarse aggregates. The properties (specific gravity, absorption capacity, abrasion) of recycled aggregates collected from 33 different sites show very similar quality compared to the quality of the virgin brick aggregate concrete commonly used in Bangladesh. More than 800 concrete specimens were made with recycled coarse aggregates collected from the 33 different demolished building sites. The compressive strength of concrete made with different coarse aggregates 
(normal brick aggregate $-\mathrm{NB}$, and recycled brick aggregate $-\mathrm{RB}$ ) are shown in Figure 3. The results indicate that by reducing W/C, compressive strength of recycled aggregate concrete can be improved to the level of the normal aggregate concrete. The detailed results of this investigation were reported separately [Mohammed et al 2015a, 2013c, and 2013d].

For complete recycling of demolished concrete as coarse and fine aggregates, recycled coarse and fine aggregates were collected from two different demolished structures of age 50 years and 70 years [Mohammed et al 2015b]. The results are shown in Figures 4 5. RB50WC35NS100RFA0 indicates the case of recycled brick $(\mathrm{RB})$ aggregate concrete of age 50 years, W/C $=0.35$, natural sand $(\mathrm{NS})=100 \%$, and recycled fine aggregate $(\mathrm{RFA})=0 \%$. It is found that the compressive strength of concrete is increased with the increase of time. Reduction of water to cement ratio also increases compressive strength of concrete. No significant reduction of strength is found due to the use of recycled fine aggregate for replacement ratios of $50 \%$ and $100 \%$. The results clearly indicate that recycled fine aggregate can be used with recycled coarse aggregate for making concrete of strength more than $20 \mathrm{MPa}$ at $\mathrm{W} / \mathrm{C}=0.55$. By reducing the $\mathrm{W} / \mathrm{C}$ to 0.40 , it is possible to increase the compressive strength of concrete to $27.5 \mathrm{MPa}$. This type of concrete made with $100 \%$ recycled coarse aggregate and $100 \%$ recycled fine aggregate can be defined as $100 \%$ green concrete.

\section{UTILIZATION OF BRICK FINE AGGREGATE IN CONCRETE}

A significant amount of by-product is produced during the production of brick aggregate. This smaller aggregate (size smaller than $4.75 \mathrm{~mm}$ ) is still considered as wastage which is a great environmental concern. An investigation was made in order to find a possibility to utilize brick fine aggregate in concrete [Mohammed et al 2015c]. For possible utilization of this material in concrete as fine aggregate, mortar specimens and concrete specimens were made with different replacement ratios of brick fine aggregate and the specimens were investigated for compressive strength and tensile strength of concrete at different ages. Bricks from different sources (S1, S2, S3) were collected and crushed into fine aggregate (denoted as Brick Fine Aggregate (BFA)) for making mortar cubes and concrete samples with different replacement ratios. The coarse aggregates were also tested for grading, unit weight, absorption capacity and abrasion as per ASTM standards. The maximum size of aggregate was $20 \mathrm{~mm}$ and the grading was controlled as per ASTM C33. Mortar cubes $(50 \mathrm{~mm})$ and briquettes were made with different replacement ratios $(0 \%, 10 \%, 20 \%$, $30 \%, 40 \%$, and $50 \%$ ) of natural sand by BFA. The specimens were tested for compressive strength and tensile strength at 7, 14, and 28 days. Also, concrete cylinders of diameter $100 \mathrm{~mm}$ and height $200 \mathrm{~mm}$ were made with different replacement ratios of natural sand by BFA $(0 \%, 10 \%, 20 \%, 30 \%, 40 \%$, and $50 \%)$; cement content $=340 \mathrm{~kg} / \mathrm{m}^{3}, \mathrm{~W} / \mathrm{C}=0.50$ and 0.55 . The samples were tested for compressive strength at 28 days only. The compressive strength of mortar blocks made with different replacement ratios of BFA is shown in Figure 6. Irrespective of the sources of BFA (S1, S2, and S3), W/C ( 0.50 and 0.55$)$ and age of the specimens, the compressive strength of mortar blocks is maximum at $30 \%$ replacement ratio. Due to the higher absorption capacity of BFA compared to the natural sand, BFA helps internal curing of concrete compared to the cases with a small amount of BFA or without BFA. However, for higher replacement ratios (more than 30\%), the benefit from internal curing is suppressed by the reduction of mechanical properties of mortar due to the use of higher amount of BFA. The tensile strength of mortar blocks made with different replacement ratios of BFA, W/C, and sources of brick fine aggregate is shown in Figure 7 . With the age of the specimens, the tensile strength of mortar specimens increased. It is also found that the tensile strength is maximum at $30 \%$ replacement of natural sand by BFA. 


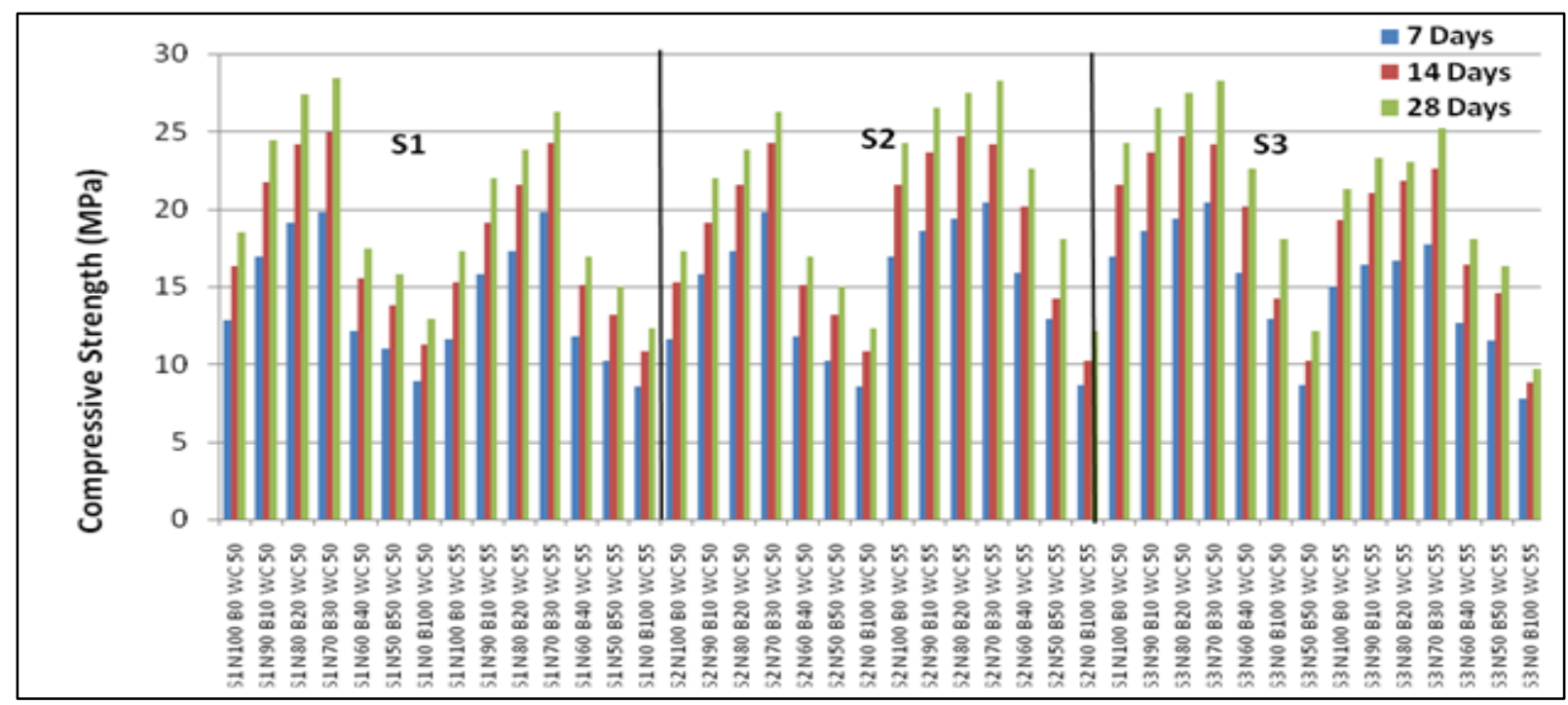

Figure 6. Compressive Strength of Mortar Blocks ( $\mathrm{S}$ indicates sources of aggregate (varied as S1, $\mathrm{S} 2$, and S3); $\mathrm{N}$ indicates natural sand (varied as 100\%, 90\%, 80\%, 70\%, 60\%, 50\%); B indicates brick fine aggregate (replacement ratio is varied as $0 \%, 10 \%, 20 \%, 30 \%, 40 \%$, and $50 \%$ ), WC indicates water to cement ration (varied as 0.50 and 0.55 ).

The 28-day compressive strength of cylinder specimens is shown in Figure 7 for different sources of BFA, different replacement ratio of BFA, and different W/C. Irrespective of the sources of BFA, it is found that with the increase of W/C, the compressive strength of concrete is reduced. Same as mortar blocks, it is found that the compressive strength of concrete is maximum at $30 \%$ replacement of natural sand by BFA. Same as compressive strength of concrete, it is found that the tensile strength of concrete is maximum at $30 \%$ replacement of natural sand by BFA. These data are not included in this report due to the space limitation.

\section{UTILIZATION OF INDUCTION FURNACE SLAG AS COARSE AGGREGATE}

Steel slag aggregate was collected from a local steel manufacturing company for investigation. The slag aggregates were separated into three types, such as lightweight slag aggregate (SL), heavyweight slag aggregate $(\mathrm{SH})$, and mixed slag aggregate $(\mathrm{SM})$. For comparison with slag aggregate, first class brick aggregate was also investigated. The aggregates were tested for absorption capacity, unit weight, and abrasion resistance. A total of 82 concrete specimens were made with slag aggregate and 82 concrete specimens were made with brick aggregate, with different W/C ratio, sand to aggregate volume ratio (s/a), and cement content. The specimens were tested for ultrasonic pulse velocity (UPV) and compressive strength at the age of 7 days and 28 days, and splitting tensile strength at 28 days.

The compressive strength of concrete made with different types of slag and brick aggregates is shown in Figure 8. It is found that concrete made with SH gives the highest compressive strength compared to the other slag and brick aggregates. Concrete made with SL gives lower compressive strength compared to the similar concrete made with brick aggregate. However, concrete made with SM and SH show higher compressive strength. It is also understood that the concrete made with the mixed slag aggregate (SM) gives similar or better compressive strength compared to the concrete made with brick aggregate. 


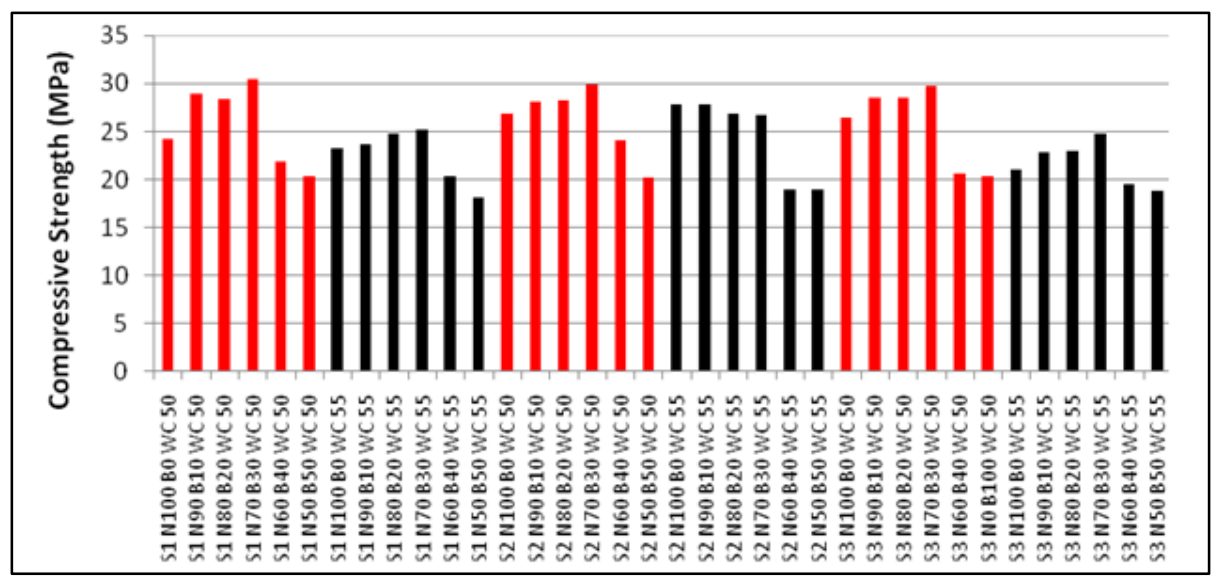

Figure 7. Compressive Strength of Concrete

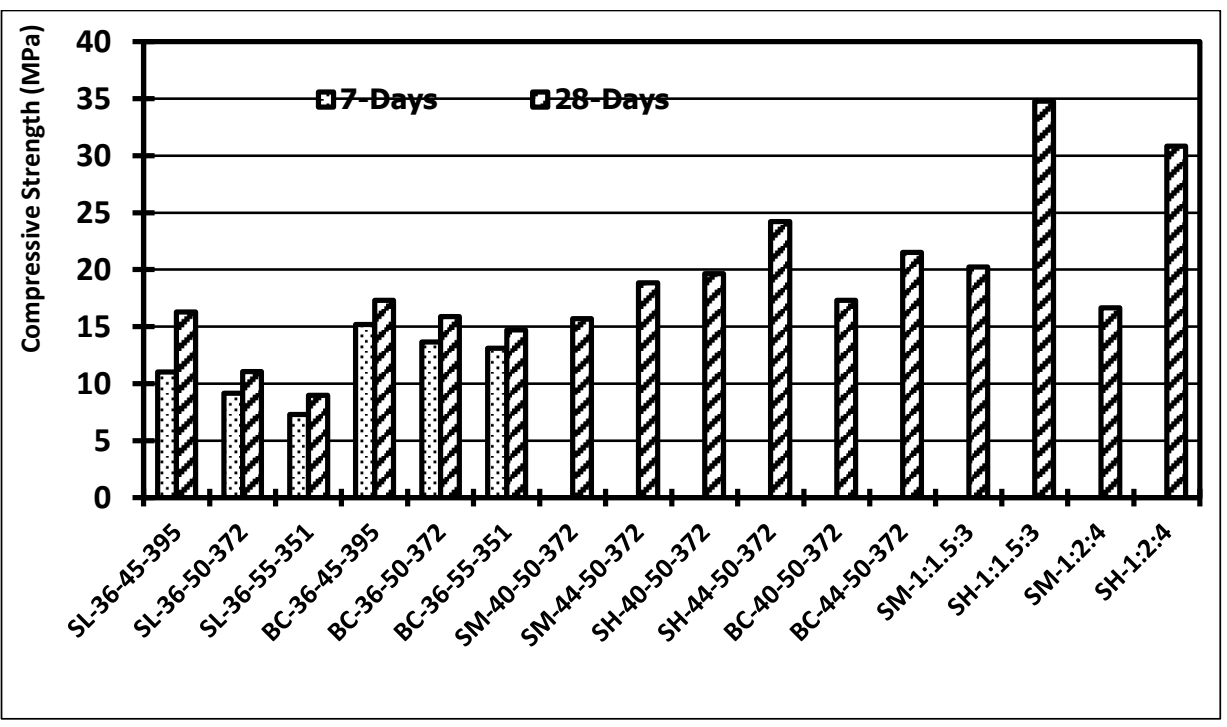

Figure 8. Compressive Strength of Concrete (Notations: SL - Lightweight slag, SH - Heavyweight slag, SM - Mixed slag, BC - Brick chips. The first two digits indicate W/C, the second two digits indicate sand to aggregate volume ratio in $\%$, and the last three digits indicate cement content in $\mathrm{kg} / \mathrm{m}^{3}, \mathrm{SM}-1: 1.5: 3$ denotes volume ratio of Cement: Fine Aggregate: Coarse Aggregate).

\section{CONCLUSION}

Based on the field and laboratory investigations, the following conclusions are made for the sustainable development of construction materials in Bangladesh:

1. Carbonation and chloride induced corrosion of steel in concrete are found to be main reasons against deterioration of concrete structures in normal atmospheric and marine exposure, respectively,

2. To increase service life of structures, carbonation coefficient is to be reduced by increasing strength of concrete as well as cover depth of concrete structures, 
3. To enhance sustainability of construction materials as well as to reduce pollution of environment from cement production, utilization of cements made with mineral admixtures can be recommended in general construction works,

4. Demolished concrete can be utilized for new construction works as coarse aggregate and fine aggregate,

5. By utilizing $100 \%$ recycled coarse aggregate and $100 \%$ recycled fine aggregate, it is possible to make concrete of strength over $27.5 \mathrm{MPa}$,

6. The optimum replacement ratio of natural sand by brick fine aggregate (BFA) with respect to compressive strength and tensile strength of concrete is found at $30 \%$, and

7. Induction furnace slag can be utilized as coarse aggregate for normal strength concrete.

\section{REFERENCES}

Armstrong T. (2013). “An Overview of Global Cement Sector Trends.” International cement review. XXX Technical Congress, FICAM-APCAC, Lima, Peru.

Mohammed, T. U., Hasnat, A., Awal, M. A., Bosunia, S. Z., (2015a). "Recycling of Brick Aggregate Concrete as Coarse Aggregate", Journal of Materials in Civil Engineering, Vol. 27, No. 7, July 2015, CID: B4014005,(doi: http://dx.doi.org/10.1061/(ASCE)MT.1943-5533.0001043).

Mohammed, T. U., Khan, A. Z., and Mahmood A. H., (2015b). "Recycling of Demolished Concrete as Coarse and Fine Aggregate". Proceedings of the International Conference on Regeneration and Conservation of Concrete Structures (RCCS), Nagasaki, Japan,Paper No. I-22, 1-12.

Mohammed, T. U., Hasan, M. (2015c). "Utilization of Brick Fine Aggregate in Concrete". Proceedings of the International Conference on Regeneration and Conservation of Concrete Structures (RCCS), Nagasaki, Japan, Paper No. I-21, 1-11.

Mohammed, T. U. (2013a). "Sustainable Development of Concrete Construction Works in Bangladesh." Third International Conference on Sustainable Construction Materials and Technologies (SCMT3), Kyoto, Japan, CD - Proceedings, Paper No. 205.

Mohammed, T. U. Mohammad, N. I., Sutradhar, S. K., Chowdhury, M. H. R., Hasnat, A, Khatib, J. M., (2013b). "Carbonation Coefficient of Concrete in Dhaka City", Proceedings of the Third International Conference on Sustainable Construction Materials and Technologies (SCMT3), August 18 21, 2013, Kyoto, Japan, CD - Proceedings. Paper No. 208.

Mohammed, T. U., Hasnat, A., Awal, M. A., and Shamim Z. Bosunia (2013c). "Recycling of Brick Aggregate Concrete: Physical and Mechanical Properties”, Proceedings of the Third International Conference on Sustainable Construction Materials and Technologies (SCMT3), August 18 21, 2013, Kyoto, Japan, CD - Proceedings. Paper No. 202.

Mohammed, T. U., Hasnat, A., Awal, M. A., , and Shamim Z. Bosunia (2013d). "Recycling of Brick Aggregate Concrete: An Extended Study on Some Key Issues", Proceedings of the Third International Conference on Sustainable Construction Materials and Technologies (SCMT3), August 18 21, 2013, Kyoto, Japan, CD - Proceedings. Paper No. 203.

Mohammed, T. U., Hasan, P., Islam, B. K. M. A., Hasnat, A., Sharkia, S. (2012). "Investigation on Different Cement Brands Commonly Used in Bangladesh." Proceedings of the Third International Conference on Construction in Developing Countries, ICCIDC III, Thailand, 554-559.

Nayan A. C. (2013). Cement sector for Bangladesh-updated, IDLC finance limited, 1-2.

World cement and concrete additives (2012). Freedonia Group, 4.

World construction Aggregate (2009). Freedonia Group, 4. 